\title{
Successful treatment of esophageal fistulas with endoscopic injection of alpha-cyanoacrylate
}

\section{monomer}

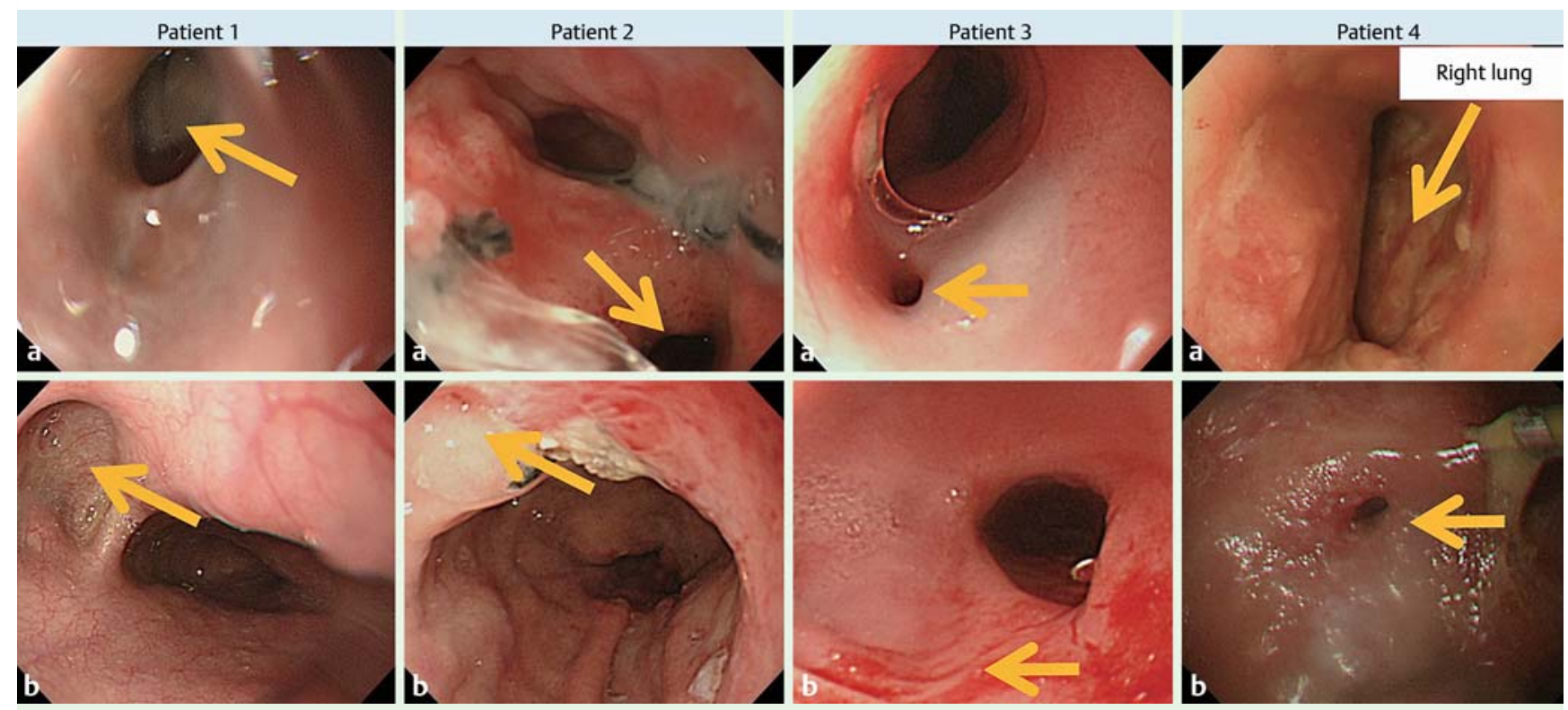

Fig. 1 The endoscopic appearance in each of the four patients showing in each case the site of the fistula (yellow arrow): a before treatment, with the fistula opening visible; $\mathbf{b}$ after treatment, with the fistula successfully closed. Note: although in patient \#4 the fistula was still slightly open, no contrast leakage was observed.

The application of glue is an established treatment for fistulas [1,2]. We consider that the alpha-cyanoacrylate monomer $(\alpha-\mathrm{CA})$ is ideal for glue embolization of intractable fistulas in the gastrointestinal tract because the $\alpha$-CA glue spreads faster, so creating a bond more rapidly than the other polymer glues, such as n-butyl cyanoacrylate polymer and 2-octyl cyanoacrylate polymer [3]. However, there have been few reports of successful fistula closure using $\alpha$-CA glue [4].

We herein report on four patients with intractable esophageal fistulas who were successfully treated with endoscopic injection of $\alpha$-CA. The causes of the fistulas were as follows: an aortoesophageal fistula that developed following a road traffic accident (Patient \#1); anastomotic leakage after esophagectomy for esophageal cancer (Patients \#2 and \#3); perforation of a colon conduit after esophagectomy for esophageal cancer (Patient \#4). In the image-guided therapy suite, a mixture of $\alpha$-CA (Aron alpha A; Sankyo, To- kyo, Japan) and oily contrast agent (Lipiodol; Guerbet, Tokyo, Japan) in a ratio of $0.3 \mathrm{~mL}: 1.7 \mathrm{~mL}$ was endoscopically injected through the fistula using a dispersion tube and a 2.5-mL glue syringe. We used $50 \%$ glucose to push the solution from the syringe into the dispersion tube. Because the presence of moisture causes the glue to set, exposure to normal levels of humidity in the air will start polymerization occurring within seconds. However, by making the glue syringe containing the $\alpha-C A$ and Lipiodol air-tight, we were able to inject the solution safely during endoscopy in the image-guided therapy suite.

The procedure was repeated every 1 or 2 weeks until the fistula was closed. In all four patients, the esophageal fistulas were successfully closed with four or six endoscopic injections of $\alpha$-CA ( $\bullet$ Fig. 1 ). This method is a feasible and safe procedure that may be effective for the treatment of nonhealing esophageal fistulas.
Endoscopy_UCTN_Code_TTT_1AO_2AI

Competing interests: None

Toshiyasu Ojima, Mikihito Nakamori, Masaki Nakamura, Masahiro Katsuda, Takeshi lida, Keiji Hayata, Katsunari Takifuji, Makoto Iwahashi, Shuichi Matsumura, Tomoya Kato, Junya Kitadani, Hiroki Yamaue

Second Department of Surgery, Wakayama Medical University,

Wakayama, Japan

\section{References}

1 Cameron R, Binmoeller KF. Cyanoacrylate applications in the GI tract. Gastrointest Endosc 2013; 77: 846-857

2 Yoon JH, Lee HL, Lee OY et al. Endoscopic treatment of recurrent congenital tracheoesophageal fistula with Histoacryl glue via the esophagus. Gastrointest Endosc 2009; 69: $1394-1396$ 
3 Katada K, Sano H, Katoh Y et al. Ethyl 2-cyanoacrylate as an embolic agent for cranial arteriovenous malformations. An experimental study. Acta Radiol Suppl 1986; 369: 623-626

4 Iwata $T$, Chung $K$, Toda $M$ et al. Malignant esophagobronchial fistula with severe esophageal stenosis, successfully treated by transbronchial occlusion with cyanoacrylate glue. Endoscopy 2012; 44 (Suppl. 02): E317-E318
Bibliography

Dol http://dx.doi.org/

10.1055/s-0033-1359159

Endoscopy 2014; 46: E62-E63

(c) Georg Thieme Verlag KG

Stuttgart · New York

ISSN 0013-726X

\section{Corresponding author}

Hiroki Yamaue, MD

Second Department of Surgery Wakayama Medical University School of Medicine

811-1, Kimiidera

Wakayama 641-8510

Japan

Fax: +81-73-4466566

yamaue-h@wakayama-med.ac.jp 